\title{
An optimal design of square spiral integrated inductor using metaheuristic techniques
}

\author{
Soufiane Abi ${ }^{1}$, Hamid Bouyghf ${ }^{2}$, Benhala Bachir ${ }^{3}$, Abdelhadi Raihani ${ }^{4}$ \\ ${ }^{1,3}$ LEAB, Faculty of Sciences, University Moulay Ismail, Morocco \\ ${ }^{2}$ EEA\&TI Laboratory, Faculty of Sciences and Techniques, University Hassan II of Casablanca, Morocco \\ ${ }^{4}$ LSSDIA, ENSET, University Hassan II of Casablanca, Morocco
}

\begin{tabular}{l} 
Article Info \\
\hline Article history: \\
Received Feb 9, 2020 \\
Revised Apr 7, 2020 \\
Accepted Apr 21, 2020 \\
\hline Keywords: \\
Integrated spiral inductor \\
Metaheuristics \\
Optimization \\
Quality factor
\end{tabular}

Quality factor

\begin{abstract}
In this paper, the optimal sizing of CMOS RF square spiral integrated inductor utilizing three meta-heuristic techniques namely Ant Colony Optimization, Artificial Bee Colony and Differential Evolution is presented. The $\pi$-model is employed for the characterization of inductor behavior. In this optimization procedure, the geometrical parameters of the CMOS RF square spiral integrated inductor are considered as the design variables that satisfy the most important constraints such as the fixed value of required inductance $4 \mathrm{nH}$ at the operating frequency $2.4 \mathrm{GHz}$. The design of the integrated square spiral inductor is done with UMC $130 \mathrm{~nm}$ CMOS technology. A comparison between the used meta-heuristic techniques is emphasized. The optimization results are checked and validated by the mean of the momentum advanced design system (ADS).
\end{abstract}

Copyright $@ 2020$ Institute of Advanced Engineering and Science. All rights reserved.

\section{Corresponding Author:}

Soufiane Abi,

Faculty of Sciences, University Moulay Ismail,

BP 11201, Zitoune, Meknes, Morocco.

Email: soufianeabi@gmail.com

\section{INTRODUCTION}

Integrated spiral inductors are widely employed in RF integrated circuits, such as a voltage controlled oscillator (VCO), mixers and low noise amplifier (LNA) [1]. Yet, achieving better performances for spiral inductors is a designing challenge and also a critical step in the design flux. The optimization of inductor depends on the applications used. This may be a high quality factor Q, a small area of the device, or small parasitic effects, etc. To simulate and optimize the performance of spiral inductors, models of the latter are needed. A lot of models for spiral inductors have been proposed like the simple- $\pi$ [2], T-models [3], double- $\pi$ [4], and enhanced simple- $\pi$ [5]. Over the last two decades, research on optimization methods of spiral inductor has oriented on the maximizing the inductor's factor of quality $(\mathrm{Q})$ for a defined operating frequency and inductance value [6]. Furthermore, the optimization of inductor depend strongly on their geometric parameters.

Severals meta-heuristic techniques have been proposed in the literature, such as genetic algorithm (GA) [7, 8] and Differential Evolution [9-11]. Among the metaheuristics offering the best results are those inspired by nature. They are efficient, resourceful, and called swarm intelligence techniques (SI) [12]. SI techniques concentrate on animal and insects conduct for developing some meta-heuristics, namely particle swarm optimization (PSO) [13], artificial bee colony (ABC) [14, 15] and ant colony optimization (ACO) [16, 17]. We concentrate in this article on the use of three meta-heuristic techniques namely Artificial Bee Colony, Ant Colony Optimization and Differential Evolution for the optimal sizing of RF integrated square spiral inductors. This paper is stuctured as follows. An overview of the used meta-heuristics is highlighted in Section 2. The inductor $\pi$-model and the design description by means of the $\mathrm{ABC}, \mathrm{ACO}$ and $\mathrm{DE}$ algorithms are presented in Section 3 . Section 4 presents the results and discussion. Finally, conclusions are given in Section 5. 


\section{DESCRIPTION OF THE USED METAHEURISTICS}

\subsection{Artificial bee colony algorithm}

In 2007 D. Karabora [18] propose the artificial bee colony algorithm (ABC). This algorithm is a swarm intelligence based algorithm that mimics the intelligent cooperative foraging behavior of honey bees [19] and it is employed for solving a large variety of difficult optimization problems [20]. The ABC algorithm contains three groups of bees that are employed, onlooker and scout bees. Employed bees goes to search the food sources and return to the hive and exchange the information with onlooker bees about food sources quality and positions by waggle dance. Onlooker bees choose the food sources according to the dance moves. The food sources that been abandoned by employed bee becomes a scout and begin looking for a new food source.

In the optimization problem, the position of the food source corresponds to a possible solution and the nectar amount of a food source represents the fitness of the associated solution. Moreover, the number of onlooker or employed bees represent the number of solutions. Initially, the ABC algorithm generates an initial population of SN solutions randomly. Each solution xi $(1,2, . ., \mathrm{SN})$ is a vector with D elements, where SN corresponds to the size of employed or onlooker bees, and $\mathrm{D}$ is the number of design variables. The positions of the population are repeated until the criteria are satisfied. Each employed bee xi generates a new food source Vi by using the (1):

$$
v_{i}^{j}=x_{i}^{j}+\phi_{i}^{j} *\left(x_{i}^{j}-x_{k}^{j}\right)
$$

where $\mathrm{k} \epsilon\{1,2, \ldots, \mathrm{SN}\}, \mathrm{j} \epsilon\{1,2, \ldots, \mathrm{D}\}$ are random indexes with $\mathrm{i} \neq \mathrm{k}$, and $\emptyset_{\mathrm{i}}^{\mathrm{j}}$ is a random number chosen between $[-1,1]$. After the search mechanism is completed by the employed bees, each onlooker bee chooses a food source according to the fitness value provided from the employed bees with a probability using the (2):

$$
\mathrm{P}_{\mathrm{i}}=\frac{\mathrm{fit}_{\mathrm{i}}}{\sum_{\mathrm{n}=1}^{\mathrm{SN}} \mathrm{fit}_{\mathrm{n}}}
$$

where fit $_{i}$ is the fitness value of the solution $i$. The employed bee modify the position and verify the nectar quantity of the candidate source. The onlooker bee saves the new position and deletes the old one if the nectar amount is superior to the previous one. The scouts bee generate a new food source according to the (3):

$$
x_{i}^{j}=x_{\text {min }}^{j}+\operatorname{rand}(0,1) *\left(x_{\text {max }}^{j}-x_{\text {min }}^{j}\right)
$$

where $x_{\min }^{j}$ is the lower bound of the dimension $j$ and $x_{\max }^{j}$ is the upper bound of the dimension $j$. The ABC algorithm pseudocode is the following:

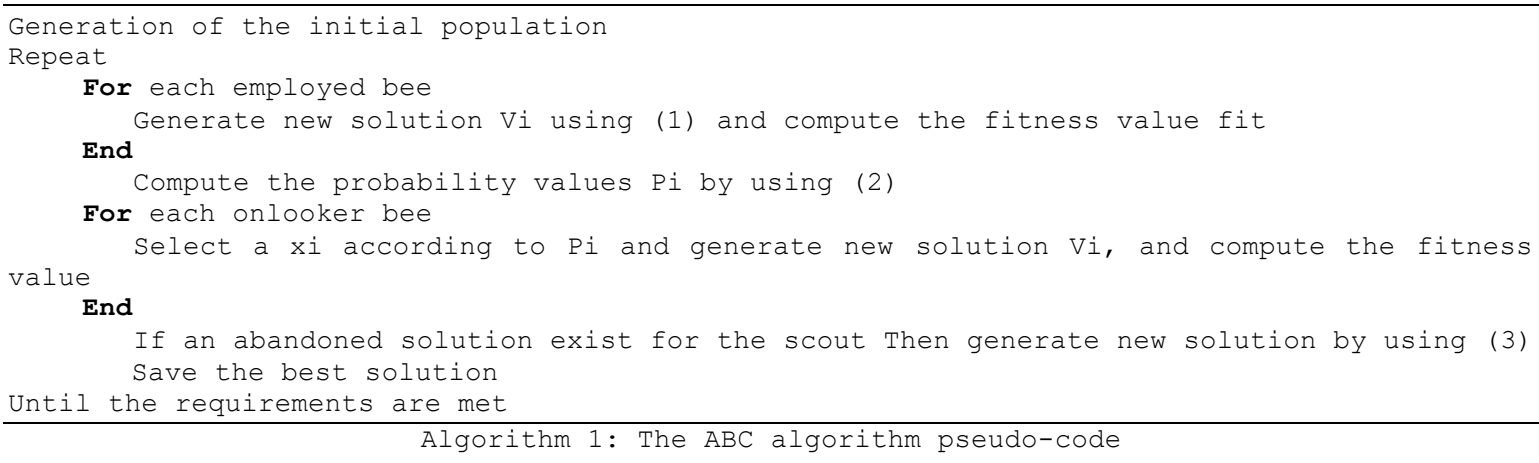

\subsection{Ant colony optimization algorithm}

The ant colony optimization (ACO) is a meta-heuristic technique that mimics the foraging behavior of ant colonies, which is consist of seeking the shortest path between their nests and food sources. ACO was initially employed to solve graph related problems, like the traveling salesman problem (TSP) [21], the opportunistic routing [22] and the optimal power flow [23]. To solve such problems, ants randomly choose the vertex to be visited. The probability that an ant $\mathrm{k}$ is located in the vertex $\mathrm{i}$, and want to go to the vertex $\mathrm{j}$ is calculated by the (4): 


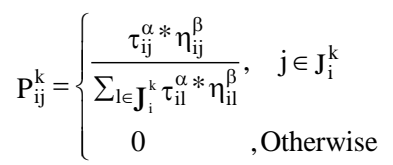

where $J_{i}^{k}$ is the neighbors of vertex $i$ of the $k^{\text {th }}$ ant, $\tau_{i j}$ is the quantity of pheromone trail on edge(i,j), $\alpha$ and $\beta$ are the weights that control the quantity of pheromone trail and the visibility value $\eta_{\mathrm{ij}}$, which is given by (5):

$$
\eta_{i j}=\frac{1}{d_{i j}}
$$

$\tau_{\mathrm{ij}}$ : is the distance between vertices $\mathrm{i}$ and $\mathrm{j}$.The updating of the pheromone values is carried out each iteration by all the $\mathrm{m}$ ants that have construct a solution in the iteration itself.The pheromone $\tau_{\mathrm{ij}}$, on the edge joining vertices $\mathrm{i}$ and $\mathrm{j}$, is updated as follows:

$$
\tau_{\mathrm{ij}}=(1-\rho) * \tau_{\mathrm{ij}}+\sum_{\mathrm{k}=1}^{\mathrm{m}} \Delta \tau_{\mathrm{ij}}^{\mathrm{k}}
$$

where $\rho$ is the pheromone evaporation rate, $\mathrm{m}$ is the number of ants, and is the quantity of pheromone deposited on edge $(i, j)$ by ant $k$ :

$$
\Delta \tau_{\mathrm{ij}}^{\mathrm{k}}= \begin{cases}\frac{\mathrm{Q}}{\mathrm{L}^{\mathrm{k}}}, & \text { if ant k used edge }(\mathrm{i}, \mathrm{j}) \text { in its tour } \\ 0, & \text { Otherwise }\end{cases}
$$

$\mathrm{Q}$ is a constant and $\mathrm{L}^{\mathrm{k}}$ is the length of the tour build by ant $\mathrm{k}$. The pseudo-code of the ACO procedure can be presented as follows:

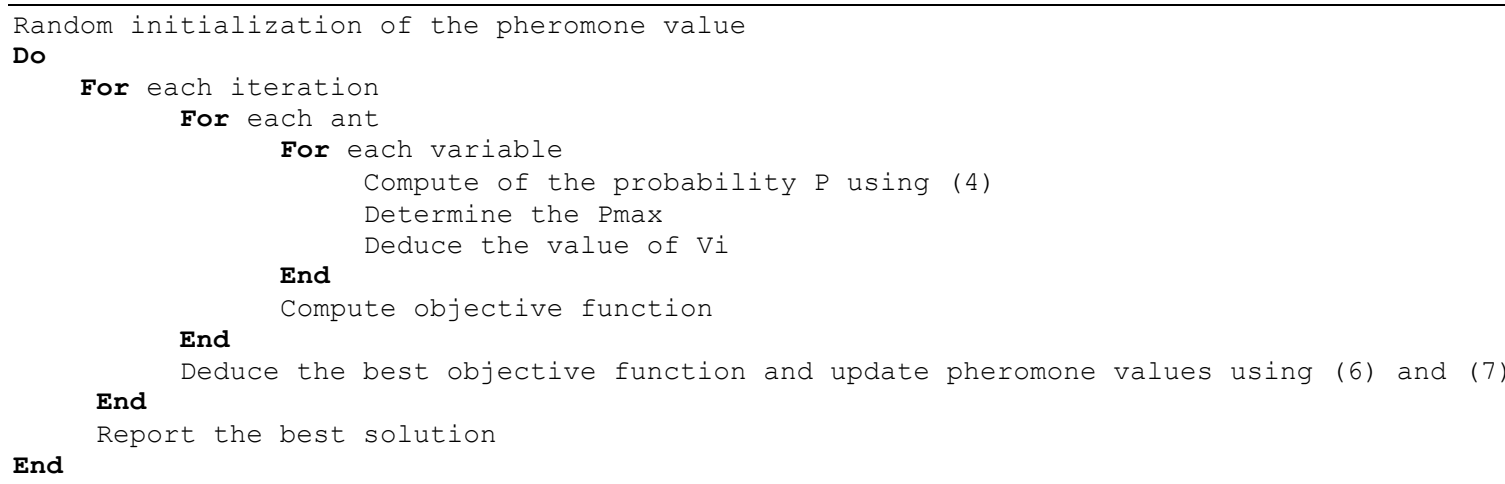

Algorithm 2: Pseudo-code of the ACO algorithm

\subsection{Differential evolution algorithm}

Differential evolution (DE) is an evolutionary meta-heuristic approach proposed by R. Storn and K. Price in 1995 [11], and is a stochastic and population-based optimization algorithm. The algorithm utilizes three main operations: mutation, crossover, and selection. And these operations are defined as follows:

$$
\mathrm{V}_{\mathrm{i}}^{\mathrm{G}+1}=\mathrm{X}_{\mathrm{r} 1}^{\mathrm{G}}+\mathrm{F} *\left(\mathrm{X}_{\mathrm{r} 2}^{\mathrm{G}}-\mathrm{V}_{\mathrm{r} 3}^{\mathrm{G}}\right)
$$

$V_{i}^{G+1}$ is a mutant vector obtained by applying the differential mutation operation. Where $\mathrm{G}$ is the generation number. $\mathrm{r} 1, \mathrm{r} 2$, and $\mathrm{r} 3(\mathrm{r} 1 \neq \mathrm{r} 2 \neq \mathrm{r} 3 \neq \mathrm{i})$ are mutually integers randomly selected from the range between 1 and NP (number of population) and $\mathrm{F}$ is a scaling factor in the optimal range of $[0.5,1.0]$. After the mutation, crossover operation is employed to generate a trial vector by choosing solution component values either from or the target vector using the following equation:

$$
\mathrm{U}_{\mathrm{ij}}^{\mathrm{G}}= \begin{cases}\mathrm{V}_{\mathrm{ij}}^{\mathrm{G}}, & \text { if }(\operatorname{randj} \leq \mathrm{CR}) \text { or }(\mathrm{j}=\mathrm{jrand}) \\ \mathrm{X}_{\mathrm{ij}}^{\mathrm{G}}, & \text { Otherwise }\end{cases}
$$


where $\mathrm{j}=1,2, \ldots, \mathrm{NP}, \operatorname{randj} \epsilon[0,1], \mathrm{CR}$ is the crossover probability $\epsilon[0,1]$ and jrand is a randomly selected index $\epsilon\{1,2, \ldots, N P\}$. After the crossover, the selection operation is employed in which the trial vector $V_{i}^{G+1}$ replaces the target vector $V_{i}^{G+1}$ if the fitness value of the trial vector is superior to the target vector, otherwise, the target vector is kept for the next generation. The selection operation is described as:

$$
X_{i j}^{G+1}= \begin{cases}U_{i j}^{G}, & \text { if } f\left(U_{i j}^{G}\right) \leq f\left(X_{i j}^{G}\right) \\ X_{i j}^{G}, & \text { Otherwise }\end{cases}
$$

where $\mathrm{f}$ is the fitness function. The DE algorithm has pseudo-code as follows:

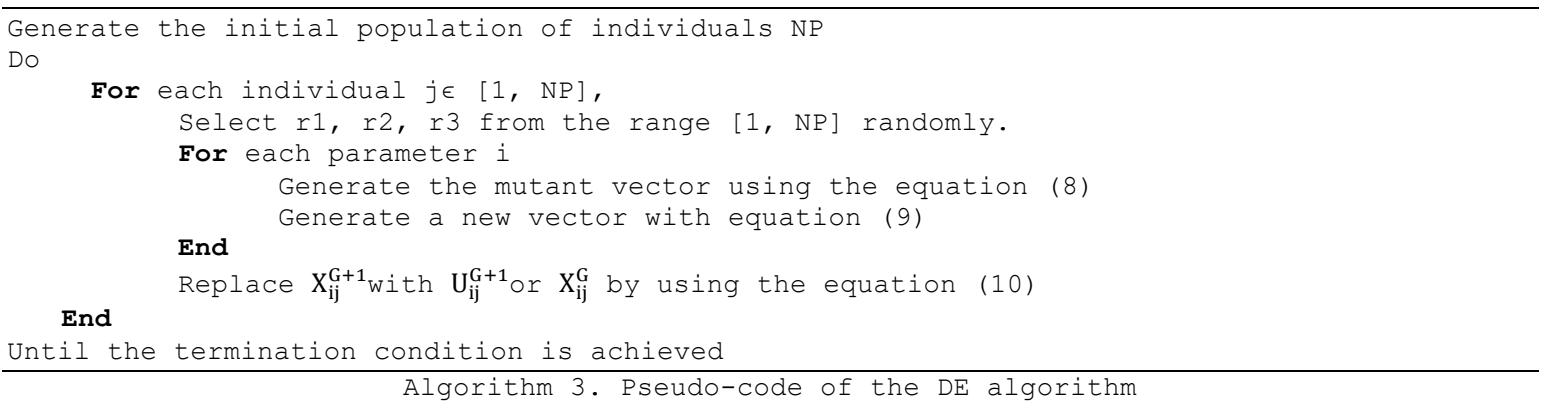

\section{EXAMPLE APPLICATION: SQUARE SPIRAL INDUCTOR}

\subsection{Layout variables for optimization}

In our study, we use the $\pi$-model, which is widely used for inductors operating in a frequency range up to a few GHz. The square spiral inductor dimensions are presented in Figure 1. The geometry parameters characterizing the spiral inductor are the number of turns (n), the trace width (W), the turn spacing (S), and the outer diameter Dout. Din is inner diameter. The main objective on the use of ABC, ACO and DE algorithms is to generate the optimal geometrical parameters of integrated spiral inductors, which will result at the required frequency a high quality factor.

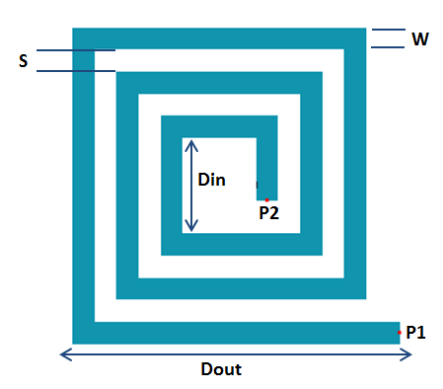

Figure 1. Layout of a square inductor

\subsection{Analysis of the spiral inductor model}

The physical model of the spiral inductor on silicon [24] is widely used in microelectronic RF design. A procedure is developed in [25] to orient parameter extraction based on the measured two-port S-parameters. Figure 2(a) presents the physical model of the inductor, which Rs, Rsi, Cs, Cox, Csi and Ls are the model parameters. Where Ls is the inductance of the spiral, Cox is the capacitance between the spiral and the silicon substrate. Rsi is the resistance, Csi is the capacitance of the substrate, and Cs is the parallel-plate capacitance between the spiral and the centertap underpass. The simplified equivalent circuit presented in Figure 2(b) is considered to compute the inductance value. Therefore, the inductance value for a given frequency (f) is calculated by the following [25]:

$$
\mathrm{L}_{\mathrm{s}}=-\frac{1}{2 \pi \mathrm{f}} \operatorname{Im}\left(\frac{1}{\mathrm{Y}_{12}}\right)
$$




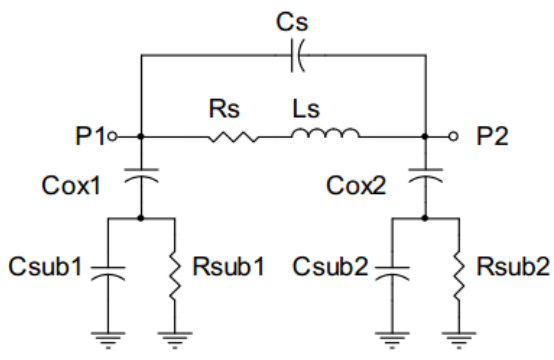

(a)

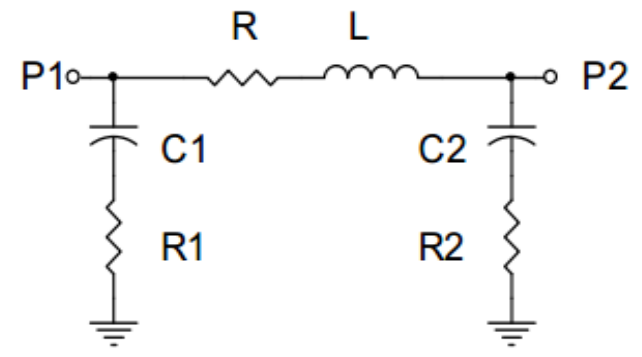

(b)

Figure 2. (a) Physical model of a spiral inductor [26, 27], (b) simplified equivalent circuit for calculating inductance value

where, Csub1=Csub2 $=$ Csi and Rsub1=Rsub2 $=$ Rsi. The expression of the parameters Cs, Rs, Csi, Rsi, and Cox are given by the following as shown in [26, 27]:

$$
\begin{aligned}
& \mathrm{C}_{\mathrm{s}}=\mathrm{n} * \mathrm{w}^{2} * \frac{\varepsilon_{\mathrm{ox}}}{\mathrm{t}_{\mathrm{oxM} 1-\mathrm{M} 2}} \\
& \mathrm{R}_{\mathrm{s}}=\frac{1}{\mathrm{w}^{*} \sigma^{*} \delta *\left(1-\mathrm{e}^{-\mathrm{t} / \delta}\right)} \\
& \mathrm{C}_{\mathrm{si}}=\frac{1}{2} * 1 * \mathrm{~W}^{*} \mathrm{C}_{\mathrm{sub}} \\
& \mathrm{R}_{\mathrm{si}}=\frac{2}{1 * \mathrm{w}^{*} \mathrm{G}_{\mathrm{sub}}} \\
& \mathrm{C}_{\mathrm{ox}}=\frac{1}{2} * 1 * \mathrm{w} * \frac{\varepsilon_{\mathrm{ox}}}{\mathrm{t}_{\mathrm{ox}}} \\
& \delta=\sqrt{\frac{2}{\omega * \mu_{0}^{* \sigma}}}
\end{aligned}
$$

where $\sigma$ is the metal conductivity at $\mathrm{dc}, \delta$ is the metal skin depth, $\mathrm{t}$ is the metal thickness, $\mathrm{t}_{\mathrm{oxM} 1-\mathrm{M} 2}$ is the oxide thickness between spiral and centertap, tox is the oxide thickness between spiral and substrate, 1 is the overall length of spiral, w is the line width, Gsub is the substrate conductance per unit area, and Csub is the substrate capacitance per unit area. The parallel equivalent circuit showed in Figure 3, is used to deduce the expression of the quality factor $(\mathrm{Q})$ [27].

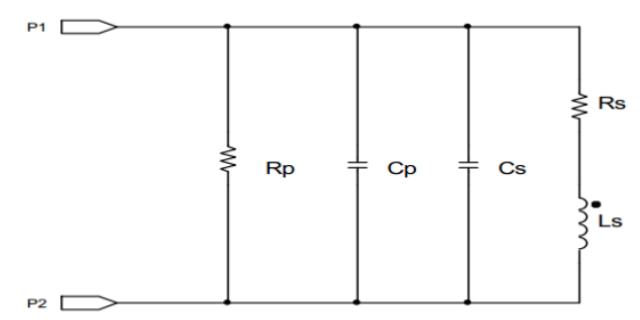

Figure 3. The parallel equivalent circuit of the spiral inductor 
The quality factor $(\mathrm{Q})$ can be expressed as follows [25]:

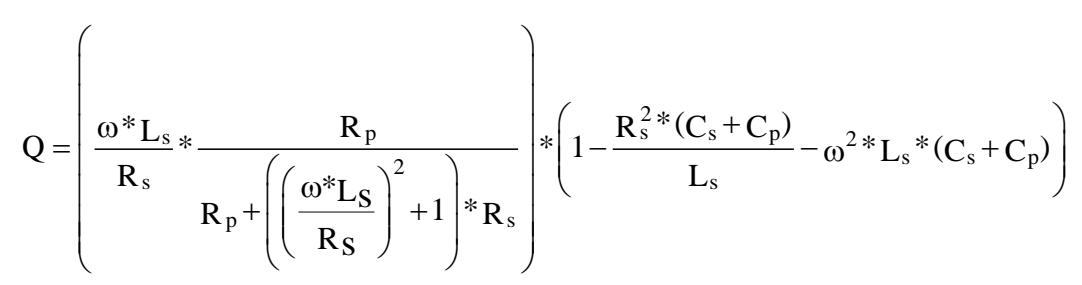

where,

$$
\begin{aligned}
& \mathrm{C}_{\mathrm{P}}=\mathrm{C}_{\mathrm{ox}} \frac{1+\omega^{2} *\left(\mathrm{C}_{\mathrm{ox}}+\mathrm{C}_{\mathrm{si}}\right) * \mathrm{C}_{\mathrm{si}} * \mathrm{R}_{\mathrm{si}}^{2}}{1+\omega^{2} *\left(\mathrm{C}_{\mathrm{ox}}+\mathrm{C}_{\mathrm{si}}\right)^{2} * \mathrm{R}_{\mathrm{si}}^{2}} \\
& \mathrm{R}_{\mathrm{P}}=\frac{1}{\omega^{2 * \mathrm{C}_{\mathrm{ox}}{ }^{2} \mathrm{R}_{\mathrm{si}}}+\mathrm{R}_{\mathrm{si}}\left(1+\mathrm{C}_{\mathrm{Si}} / \mathrm{C}_{\mathrm{ox}}\right)^{2}}
\end{aligned}
$$

the quality factor has another expression which is computed from theY-parameters [25]:

$$
Q=-\frac{\operatorname{Im}\left(Y_{11}\right)}{\operatorname{Re}\left(Y_{11}\right)}
$$

the (21) is used for calculating the quality factor by using the Y-parameters obtained from EM-simulator (Momentum ADS). The expression of the inductance Ls is given by the following [25, 27]:

$$
\begin{aligned}
& \mathrm{L}_{\mathrm{s}}=\beta^{*} \mathrm{D}_{\text {out }}^{\alpha 1} * \mathrm{~W}^{\alpha 2 *} \mathrm{D}_{\mathrm{avg}}^{\alpha 3} * \mathrm{n}^{\alpha 4 *} \mathrm{~S}^{\alpha 5} \\
& \mathrm{D}_{\mathrm{avg}}=0.5 *\left(\mathrm{D}_{\text {out }}+\mathrm{D}_{\text {in }}\right) \\
& \mathrm{D}_{\text {out }}=\mathrm{D}_{\text {in }}+2 * \mathrm{n} * \mathrm{~W}+2 *(\mathrm{n}-1) * \mathrm{~S}
\end{aligned}
$$

$\beta$ and $\alpha_{\mathrm{i}}(\mathrm{i}=1,2, \ldots, 5)$ are the coefficients depend on the inductor topology. The coefficients for square inductor are $[25,27]: \beta=1.62 \mathrm{e}-3, \alpha_{1}=-1.21, \alpha_{2}=-0.147, \alpha_{3}=2.4, \alpha_{4}=1.78, \alpha_{5}=-0.03$.

\subsection{Problem formulation}

The expression of the as shown in (18) is employed as a cost function (CF). Moreover, the formulation of the design problem of the spiral inductor is presented as follows:

Maximize of Q-quality factor $\left(\right.$ Minimize $\left._{\mathrm{req}}\right)$ :

Subject to:

$$
\begin{aligned}
& \mathrm{Q} \geq \mathrm{Q}_{\mathrm{Lmin}} \\
& \mathrm{L}_{\mathrm{s}}=\mathrm{L}_{\mathrm{req}}
\end{aligned}
$$

where, Lreq is the required inductance. Independent geometry parameters constraints may be added such as: Number of turn: $n \leq 4$

Minimum value of the track width: $\mathrm{W} \leq 12 \mu \mathrm{m}$

Minimum of spacing: $\mathrm{S} \leq 2.5 \mu \mathrm{m}$

Outer diameter: Dout $\leq 231 \mu \mathrm{m}$

For reducing the parasitic effect owing to the proximity problem [25, 27], we will respect this added constraint:

$$
\mathrm{D}_{\text {in }}>5 \mathrm{~W} ; 0.2<\frac{\mathrm{D}_{\text {in }}}{\mathrm{D}_{\text {out }}}<0.8
$$


The object function finds the global minimum CF for its expression:

$$
\mathrm{CF}=\mathrm{Q}_{\mathrm{req}}+1.0 \mathrm{e}^{9 *} \operatorname{abs}\left(\mathrm{L}_{\mathrm{s}}-\mathrm{L}_{\text {sreq }}\right)+\text { penalty } * \operatorname{sum}(\mathrm{Ct})
$$

where, $\mathrm{Q}_{\text {req }}=\frac{1}{\mathrm{Q}}$, Penalty: penalty of each constraint violation, sum $(\mathrm{Ct})$ : some of all constraints $(\mathrm{Ct}(1)$, $\mathrm{Ct}(2)$...). The minimum value of $\mathrm{CF}$ guarantees the maximal value for Q-factor for Lsreq=4nH and Freq $=\mathrm{fs}=2.4 \mathrm{GHz}$. Table 1 summarized the technological parameters:

Table 1. Technological parameters for inductor design

\begin{tabular}{ccc}
\hline Name & Symbol & Value \\
\hline Metal thickness & $\mathrm{t}$ & $2.8 \mathrm{e}-6$ \\
Thickness of the oxide & toxM1M2 & $0.4 \mathrm{e}-6$ \\
& & \\
insulator between the spiral and underpass tM1-M2 & tox & $5.42 \mathrm{e}-6$ \\
Thickness of the oxide & $\sigma$ & $1 / 2.65 \mathrm{e}-8$ \\
Metal conductivity & Gsub & $2.43 \mathrm{e} 5$ \\
Substrate conductance & $\varepsilon 0 \mathrm{x}$ & $3.453 \mathrm{e}-11$ \\
Permitivity of the oxide & tsub & $700 \mathrm{e}-6$ \\
Substrate thickness & $\rho$ & $28 \Omega . \mathrm{cm}$ \\
Substrate resistivity & $\varepsilon \mathrm{r}$ & 11.9 \\
Substrate permitivity & $\mathrm{u}(\mathrm{mju})$ & $1.256 \mathrm{e}-6$ \\
\hline
\end{tabular}

The setting parameters of ABC, ACO and DE algorithms are presented respectively in Table 2 and this algorithms, are implemented in MATLAB. For each algorithm we choose 100 for the number of populations, and 1000 for the number of generations. For the spiral inductor design, the ABC, ACO and DE algorithms starts with creation of the initial bees, ants, and populations respectively by randomization, where each ant/bee/Pop is composed by four design variables [Dout=Ant/Bee/Pop(:1),W=Ant/Bee/Pop(:,2),S=Ant/Bee/Pop(:,3), $\mathrm{n}=\mathrm{Ant} / \mathrm{Bee} / \mathrm{Pop}(:, 4)]$, representing the layout geometry parameters, and must obey to variable boundaries.

Table 2. Algorithms parameters

\begin{tabular}{cccc}
\hline Parameters & ABC & ACO & DE \\
\hline Number of onlookers bees & $50 \%$ of the swarm & - & - \\
Number of employed bees & $50 \%$ of the swarm & - & - \\
Number of food sources & 50 & - & - \\
Pheromone factor $(\alpha)$ & - & 1 & - \\
Heuristic factor $(\beta)$ & -- & 1 & - \\
Evaporation rate $(\rho)$ & -- & 0.1 & - \\
Quantity of pheromone $(\mathrm{Q})$ & -- & 0.2 & - \\
Scaling factor $(F)$ & - & - & 0.9 \\
Crossover probability $(\mathrm{CR})$ & - & - & 0.5 \\
\hline
\end{tabular}

\section{RESULTS AND DISCUSSION}

The design and simulation results of $4 \mathrm{nH}$ inductor for an operating frequency of $2.4 \mathrm{GHz}$ are addressed using UMC 130nm CMOS technology parameters shown in Table 1. The ABC optimization results are done compared with those obtained with $\mathrm{ACO}$ and DE algorithm and verified with using an EM-simulator (Momentum ADS) [28]. Table 3 show the optimal results obtained using the ABC, ACO and DE algorithms.

Table 3. Optimization results

\begin{tabular}{cccccc}
\hline Algorithm & $\mathrm{S}(\mu \mathrm{m})$ & $\mathrm{W}(\mu \mathrm{m})$ & $\mathrm{n}$ & Dout $(\mu \mathrm{m})$ & $\mathrm{Q}$ \\
\hline $\mathrm{ABC}$ & 2.5 & 11.15 & 3.5 & 231 & 12.71 \\
$\mathrm{ACO}$ & 2.5 & 11.149 & 3.5 & 185.75 & 12.66 \\
$\mathrm{DE}$ & 2.5 & 11.15 & 3.5 & 180 & 12.59 \\
\hline
\end{tabular}

For the three algorithms, it can be noticed that the results are identical in terms of the quality factor; however, in term of circuit size, the DE technique gives a smaller circuit than the ACO and ABC algorithms. Figure 4 present the gragh convergence for each techniques and Table 4 shows the comparison between evaluated and simulated results and circuit performances through EM-simulator (Momentum ADS). 


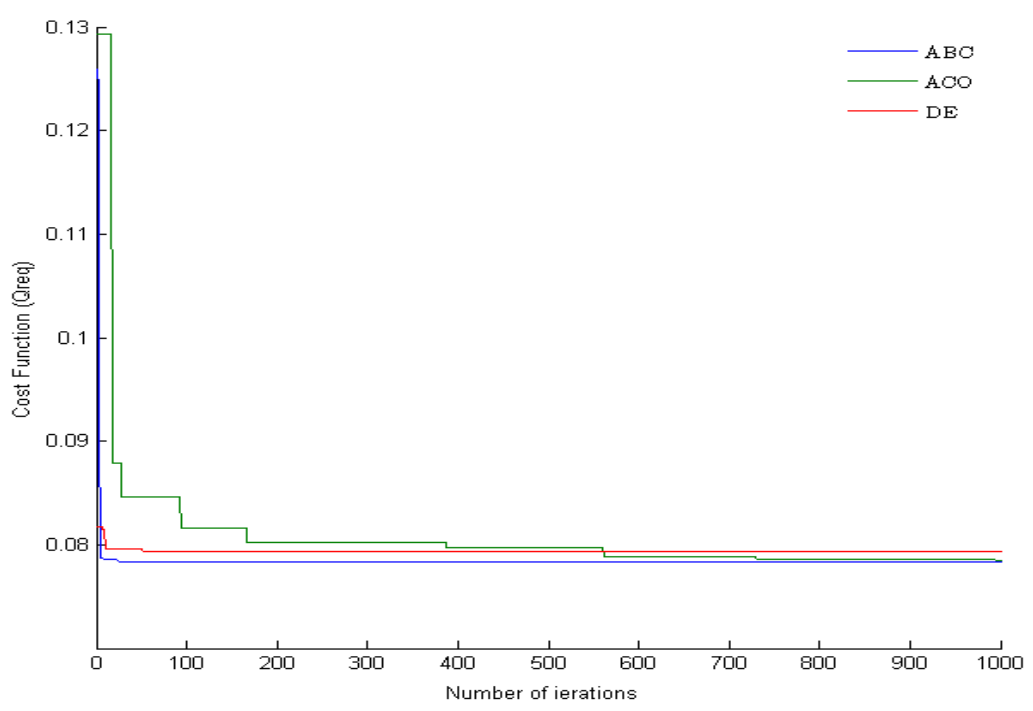

Figure 4. Cost function (Qreq) vs number of iterations for the three algorithms

Table 4. Simulation results

\begin{tabular}{ccccccc}
\hline Algorithm & $\mathrm{L}(\mathrm{nH})$ & Lsim $(\mu \mathrm{m})$ & Error $(\%)$ & $\mathrm{Q}$ & Qsim & Error $(\%)$ \\
\hline ABC & 3.96 & 3.95 & 0.25 & 12.71 & 12.25 & 3.75 \\
ACO & 2.64 & 2.61 & 1.15 & 12.66 & 12.60 & 0.4 \\
DE & 2.47 & 2.45 & 0.82 & 12.59 & 12.50 & 0.72 \\
\hline
\end{tabular}

Figures 5(a), (b) and 6 present the Momentum-ADS simulations results ( $\mathrm{Q}$ and $\mathrm{L}$ ) using the obtained optimal values by ABC, ACO and DE based methods respectively. We can notice clearly from Matlab coding results that the $\mathrm{ABC}$ technique has a fast convergence time during its optimization process as compared to the ACO and DE techniques. Also we remark that the simulation results are in corresponding with the optimization results.
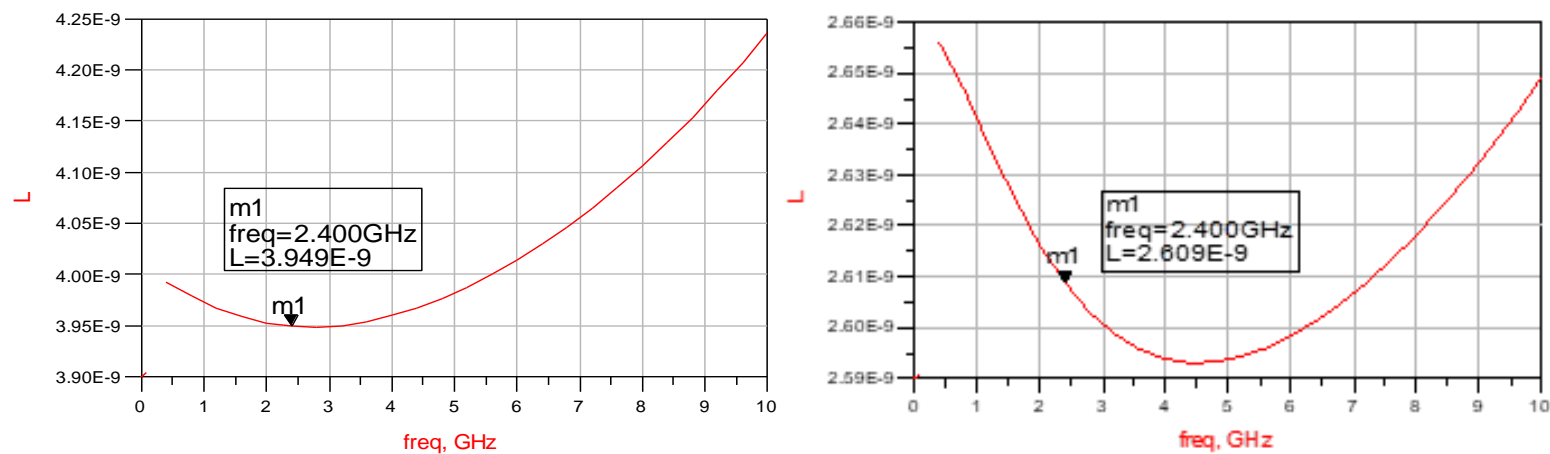

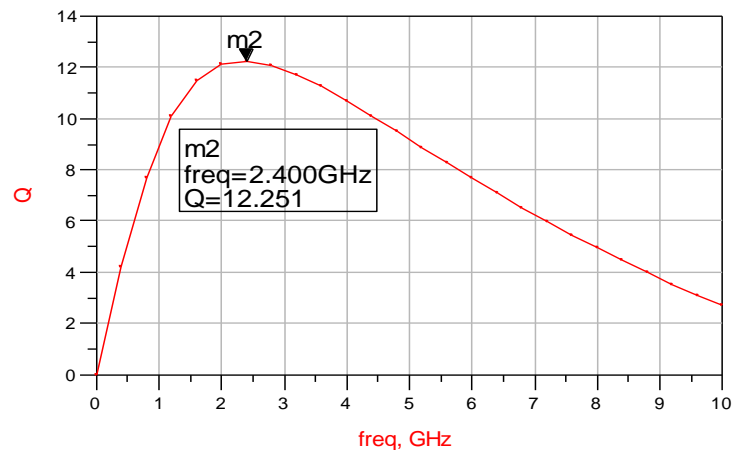

(a)

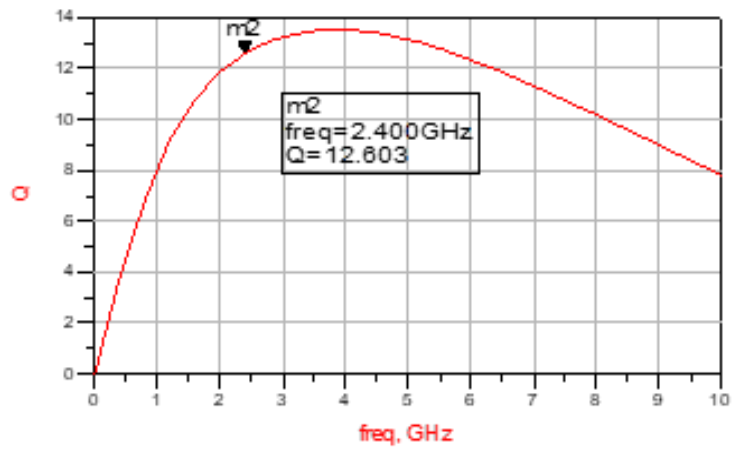

(b)

Figure 5. (a) Momentum simulation using ABC technique, (b) momentum using ACO technique 

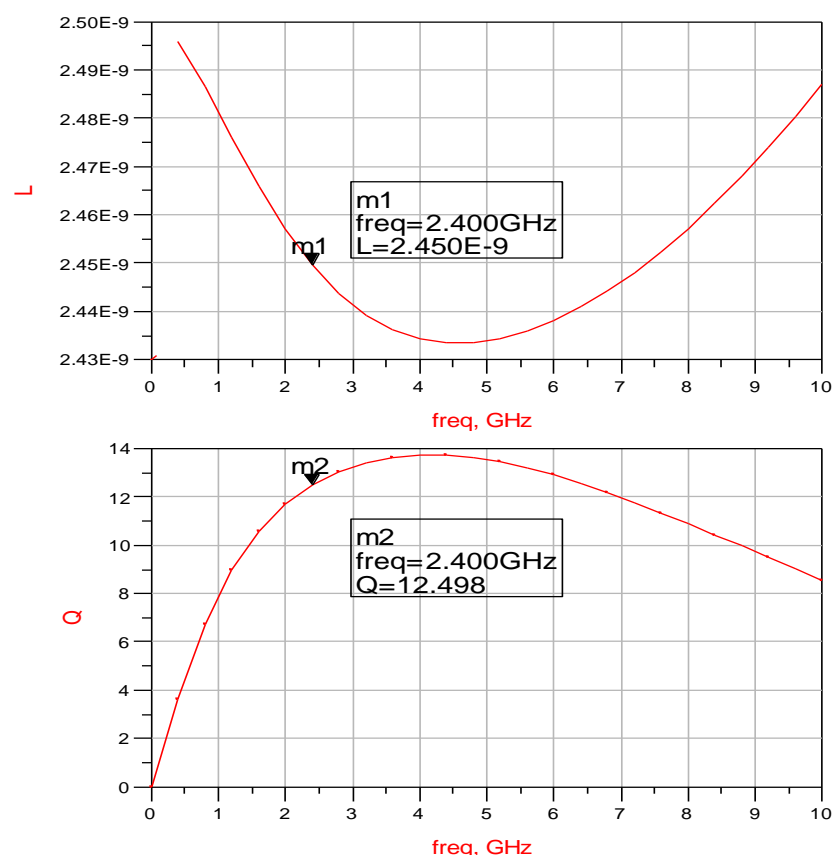

Figure 6. Momentum simulation using DE technique

\section{CONCLUSION}

In this paper, an optimal design of an integrated square spiral inductor by using three metaheuristic techniques is presented. The description of the model used for the inductor and the metaheuristic techniques were highlighted. The objective of this work is to get a higher value of the quality factor-Q taking into account the design requirements and the fundamental constraints. The optimization results show that the DE technique gives the best results in terms of circuit size, whereas the ABC technique has faster convergence. The simulation results are in good accuracy with the optimization results. We can argue that these metaheuristic algorithms can be employed to design integrated spiral inductors with a higher quality factor (Q). Our future works will be focused on exploiting the benefits of these algorithms for proposing hybrid metaheuristics.

\section{REFERENCES}

[1] H. S. Bennett, R. Brederlow, J. C. Costa, P. E. Cottrell, W. M. Huang, A. A. Immorlica, et al., "Device and technology evolution for Si-based RF integrated circuits," IEEE Transactions on Electron Devices, vol. 52, no. 7, pp. 1235-1258, 2005.

[2] E. -S. A. M. Hasaneen, "Compact circuit simulation model for on-chip inductor and transformer for RF integrated circuits," 2007 2nd International Design and Test Workshop, Cairo, 2007, pp. 265-269.

[3] J. C. Guo and T. Y. Tan, "A broadband and scalable on-chip inductor model appropriate for operation modes of varying substrate resistivities," in IEEE Transactions on Electron Devices, vol. 54, no. 11, pp. 3018-3029, 2007.

[4] F. Huang, J. Lu, N. Jiang, X. Zhang, W. Wu, Y. Wang, "Frequency-independent asymmetric double-pi equivalent circuit for on-chip spiral inductors: physics-based modeling and parameter extraction," in IEEE Journal of SolidState Circuits, vol. 41, no. 10, pp. 2272-2283, 2006.

[5] H. H. Chen, Zhang H. W., Chung S. J., Kuo J. T., Wu T. C., "Accurate systematic model-parameter extraction for on-chip spiral inductors," in IEEE Transactions on Electron Devices, vol. 55, no. 11, pp. 3267-3273, Nov. 2008.

[6] P. Pereira, F. Coito, H. Fino, "PSO-Based Design of RF Integrated Inductor," In: DoCEIS, IFIP AICT, Costa de caparica, vol. 372, pp. 475-482, 2012.

[7] B. Benhala, and O. Bouattane, "GA and ACO techniques for the analog circuits design optimization," Journal of Journal of Theoretical and Applied Mechanics, vol. 64, no. 2, pp. 413-419, 2017.

[8] A. El Beqal, B. Benhala, I. Zorkani, "A Genetic algorithm for the optimal design of a multistage amplifier," International Journal of Electrical and Computer Engineering (IJECE), vol. 10, vo. 1, pp. 129-138, 2020.

[9] S. Abi, B. Benhala, H. Bouyghf and M. Fakhfakh, "A Comparative Study between ACO and DE Techniques by Numerical Functions Optimization," 2019 5th International Conference on Optimization and Applications (ICOA), Kenitra, Morocco, pp. 1-6, 2019.

[10] S. Abi, H. Bouyghf, A. Raihani, and B. Benhala, "Swarm Intelligence Optimization Techniques for an Optimal RF Integrated Spiral Inductor Design," 2018 International Conference on Electronics, Control, Optimization and Computer Science (ICECOCS), Kenitra, pp. 1-7, 2018. 
[11] K. V. Price, R. M. Storn, J. A. Lampinen, "Differential Evolution: a practical approach to global optimization," Springer-Verlag Berlin Heidelberg, 2005.

[12] B. Benhala, P. Pereira, A. Sallem, "Focus on Swarm Intelligence Research and Applications," Nova Science Publishers, 2017.

[13] M. Fakhfakh, Y. Cooren, A. Sallem, M. Loulou, P. Siarry, "Analog Circuit Design Optimization through the Particle Swarm Optimization Technique," Analog Integrated Circuits and Signal Processing, vol. 63, no. 1, pp.71-82, 2010.

[14] H. Bouyghf, B. Benhala, A. Raihani, "Analysis of the impact of metal thickness and geometric parameters on the quality factor-Q in integrated spiral inductors by means of artificial bee colony technique," International Journal of Electrical and Computer Engineering (IJECE), vol. 9, no. 4, pp. 2918-2931, 2019.

[15] S. Abi, H. Bouyghf, B. Benhala, A. Raihani, "An Optimal Design of a Short-Channel RF Low Noise Amplifier Using a Swarm Intelligence Technique," Embedded Systems and Artificial Intelligence, vol. 1076, pp. 143-153, 2020.

[16] L. Kritele, B. Benhala, and I. Zorkani, "Ant Colony Optimization for Optimal Low-Pass State Variable FilterSizing," International Journal of Electrical and Computer Engineering (IJECE), vol. 8, no. 1, pp. 227-235, 2018.

[17] B. Benhala, "An improved aco algorithm for the analog circuits design optimization," International Journal of Circuits, Systems and Signal Processing, vol. 10, pp.128-133, 2016.

[18] D. Karaboga, B. Basturk, "A powerful and efficient algorithm for numerical function optimization: artificial bee colony (ABC) algorithm," Journal of Global Optimization, vol. 39, no. 3, pp. 459-471, 2007.

[19] D. Karaboga, "An idea based on honey bee swarm for numerical optimization," Tech. Rep.TR06, Erciyes University, Engineering Faculty, Computer Engineering Department, 2005.

[20] W. L. Chang, D. Z. Zeng, R. C. Ching, S. Guo, "An artificial bee colony algorithm for data collection path planning in sparse wireless sensor networks," International Journal of Machice Learning \& Cybernetics, vol. 6, no. 3, pp. 375-383, 2015.

[21] M. Dorigo, V. Maniezzo, A. Colorni, "The ant system: Optimization by a colony of cooperating agents," in IEEE Transactions on Systems, Man, and Cybernetics, Part B (Cybernetics), vol. 26, no. 1, pp. 29-41, 1996.

[22] S. Harikishore, V. Sumalatha, "Ant Colony Optimization based energy efficiency for improving opportunistic routing in multimedia wireless mesh network," Indonesian Journal of Electrical Engineering and Computer Science (IJEECS), vol. 16, no. 3, pp. 1371-1378, 2019.

[23] M. A. Abd. Rahman, B. Ismail, K. Naidu, M. K. Rahmat, "Review on population-based metaheuristic search techniques for optimal power flow," Indonesian Journal of Electrical Engineering and Computer Science (IJEECS), vol. 15, no. 1, pp. 373-381, 2019.

[24] C. P. Yue, C. Ryu, J. Lau, T. H. Lee, S. S. Wong, "A Physical model for planar spiral inductors on silicon," International Electron Devices Meeting. Technical Digest, San Francisco, CA, USA, 1996, pp. 155-158.

[25] V. P. Durev, E. D. Gadjeva, M. Hristov, "Analysis, Model Parameter Extraction and Optimization of Planar Inductors Using MATLAB," In: Leite EP. Editors. Modelling, Programming and Simulations, Sciyo, pp. 278-300, 2010.

[26] V. Durev, E. Gadjeva, M. Hristov, "Parameter Extraction of Geometry Dependent RF Planar Inductor Model," Proceedings of the 17th International Conference Mixed Design of Integrated Circuits and Systems-MIXDES 2010, Warsaw, pp. 420-424, 2010.

[27] K. Okada, H., Hoshino, H. Onodera, "Modeling and optimization of on-chip spiral inductor in S-parameter domain," 2004 IEEE International Symposium on Circuits and Systems (IEEE Cat. No.04CH37512), Vancouver, BC, pp. V-V, 2004.

[28] Momentum, ADS2002, “Agilent Technologies,” EEsof division, Santa Rosa, CA, 2006. 